\title{
Solar Forcing of Regional Climate Change During the Maunder Minimum
}

\author{
Drew T. Shindell, ' Gavin A. Schmidt,' Michael E. Mann, ${ }^{2}$ \\ David Rind, ${ }^{1}$ Anne Waple ${ }^{3}$
}

\begin{abstract}
We examine the climate response to solar irradiance changes between the late 17 th century Maunder Minimum and the late 18th century. Global average temperature changes are small (about 0.3 to $0.4^{\circ} \mathrm{C}$ ) in both a climate model and empirical reconstructions. However, regional temperature changes are quite large. In the model, these occur primarily through a forced shift toward the low index state of the Arctic Oscillation/North Atlantic Oscillation. This leads to colder temperatures over the Northern Hemisphere continents, especially in winter $\left(1\right.$ to $\left.2^{\circ} \mathrm{C}\right)$, in agreement with historical records and proxy data for surface temperatures.
\end{abstract}

A minimum in solar irradiance, the Maunder Minimum, is thought to have occurred from the mid-1600s to the early 1700 s $(I-3)$. Concurrently, surface temperatures appear to have been at or near their lowest values of the past millenium in the Northern Hemisphere (NH) (4-7), and European winter temperatures were reduced by 1 to $1.5^{\circ} \mathrm{C}(8)$.

We used a version of the Goddard Institute for Space Studies (GISS) general circulation model (GCM), which includes a detailed representation of the stratosphere, to simulate the difference between that period and a century later, when solar output remained relatively high over several decades. The model contains a mixed-layer ocean, allowing sea surface temperatures (SSTs) to respond to radiative forcing, and has been shown to capture observed wintertime solar cycle-induced variations reasonably well (9).

The GCM includes parameterizations of the response of ozone to solar irradiance, temperature, and circulation changes (although transport changes are noninteractive) (9), based on results for preindustrial conditions from our two-dimensional (2D) chemistry model $(10)$. These show more ozone in the upper and lower stratosphere, as expected (11), primarily because of the absence of anthropogenic halogens and a drier stratosphere (12). Ozone's temperature sensitivity was also increased throughout the upper stratosphere, more than doubling at 3 millibars (mbar) relative to the present (13). Solar heating then speeds up chemical destruction more than irradiance enhances photolytic production, so that ozone concentration de-

'NASA Goddard Institute for Space Studies and Center for Climate Systems Research, Columbia University, New York, NY 10025, USA 'Department of Environmental Sciences, University of Virginia, Charlottesville, VA 22902, USA. 'BDepartment of Geosciences, University of Massachusetts. Amherst, MA 01003, USA creases with solar output. Thus, the reduced Maunder Minimum irradiance leads to increased upper stratospheric ozone, which in turn causes lower stratospheric ozone to decrease. Both cause negative radiative forcing (14). Inclusion of ozone photochemistry therefore enhances radiative forcing from preindustrial solar variations.

Equilibrium simulations were performed for spectrally discriminated irradiances in 1680 and $1780(1)$. An alternative reconstruction has a $40 \%$ larger long-term solar variation, which would give a larger climate response (15). Initial conditions were taken from 1680 and 1780 in a transient simulation. A spin-up time of about 25 years was nevertheless required for equilibration with the increased preindustrial ozone. Results are therefore based on the past 30 years of 60 year simulations.

Modeled global annual average surface temperatures were $0.34^{\circ} \mathrm{C}$ cooler in 1680 than in 1780. This is similar to the annual average NH 1680-minus- 1780 temperature change of about $-0.2 \pm 0.2^{\circ} \mathrm{C}$ from proxy data (6) or an energy balance model (7) (model NH cooling is $-0.33 \mathrm{C}$ ). Other proxybased reconstructions for the $\mathrm{NH}$ extratropics during summer indicate a -0.3 to $-0.4^{\circ} \mathrm{C}$ cooling $(4,5)$ (comparable model cooling is $\left.-0.3^{\circ} \mathrm{C}\right)$.

Modeled surface temperature changes show alternating warm oceans and cold continents at NH mid-latitudes (Fig. 1), with maximum amplitude in winter. To characterize regional changes, we calculated empirical orthogonal functions (EOFs) from the $\mathrm{NH}$ extratropical $\left(20^{\circ}\right.$ to $90^{\circ} \mathrm{N}$ ) cold season (from November to April) sea level pressure (SLP) time series. The last 40 years of each run were used as an 80-year control.

The leading control EOF (Fig. 2) closely matches the Arctic Oscillation pattern (AO, also called the Northern Hemisphere Annular
Mode), defined as the first EOF of 20thcentury SLP (16). This pattern contains the North Atlantic Oscillation (NAO), which may be considered a different view of the same phenomenon (17). We define the model's $A O$ pattern as EOF 1, and the AO index as the opposite of the area-weighted change in SLP northward of $60^{\circ}$. Projection of the 1780-to-1680 SLP difference (Fig. 2) onto the first five control EOFs shows that they account for $37.3,0.0,3.4,1.5$, and $0.0 \%$ of the variance, respectively. Thus, the regional climate variations primarily result from a lower index state of the AO during the Maunder Minimum relative to that of a century later (by -1.1 mbar; similarly, the SLP contrast between Iceland and the Azores decreases by $1.9 \mathrm{mbar}$ ). This reduces onshore advection of warm oceanic air, yielding a $1^{\circ}$ to $2^{\circ} \mathrm{C}$ cooling over large areas of North America and Eurasia (Fig. 1).

Historical data associate the European Maunder Minimum winter cooling with enhanced northeasterly advection of continental air, consistent with an anomalous negative NAO (18). Reconstructions of large-scale surface temperature patterns in past centuries $(19,20)$ from networks of diverse proxy information (tree rings, ice cores, corals, and historical records) are particularly useful benchmarks for comparison. Correlations between these reconstructions and solar irradiance reconstructions ( $I$ ) during the preanthropogenic interval from 1650 to 1850 provide an empirical estimate of the large-scale climate response to solar forcing (2I). The instantaneous (zero-lag) frequency-independent regression pattern, primarily indicative of decadal solar-climate relationships, shows little evidence of an AO/NAO signal (Fig. 3, top). This is consistent with the extremely weak modeled AO/NAO response to the 11year solar cycle using fixed SSTs, equivalent to an instantaneous response (22). However, when filtered to isolate the multidecadal/centennial time scales associated with the Maunder Minimum, and lagged to allow for inertia in the ocean's response, the empirical regression (Fig. 3, bottom) shows a clear AO/NAOtype pattern of alternating cold land and warm ocean temperature anomalies. Both paleoclimate reconstructions and the GCM thus indicate in a remarkably consistent manner that solar forcing affects regional scales much more strongly than global or hemispheric scales through forcing of the AO/NAO.

Most additional paleoclimate data have insufficient time resolution to distinguish the Maunder Minimum but suggest a shift toward the AO/NAO low-index state during periods of reduced solar forcing. Ocean sediments show a decreased SST of 1 to $2^{\circ} \mathrm{C}$ in the Sargasso Sea during the 16th to 19th centuries, and warmer Atlantic temperatures north of $44^{\circ}$, extending to the area off Newfound- 


\section{RE P O R T S}
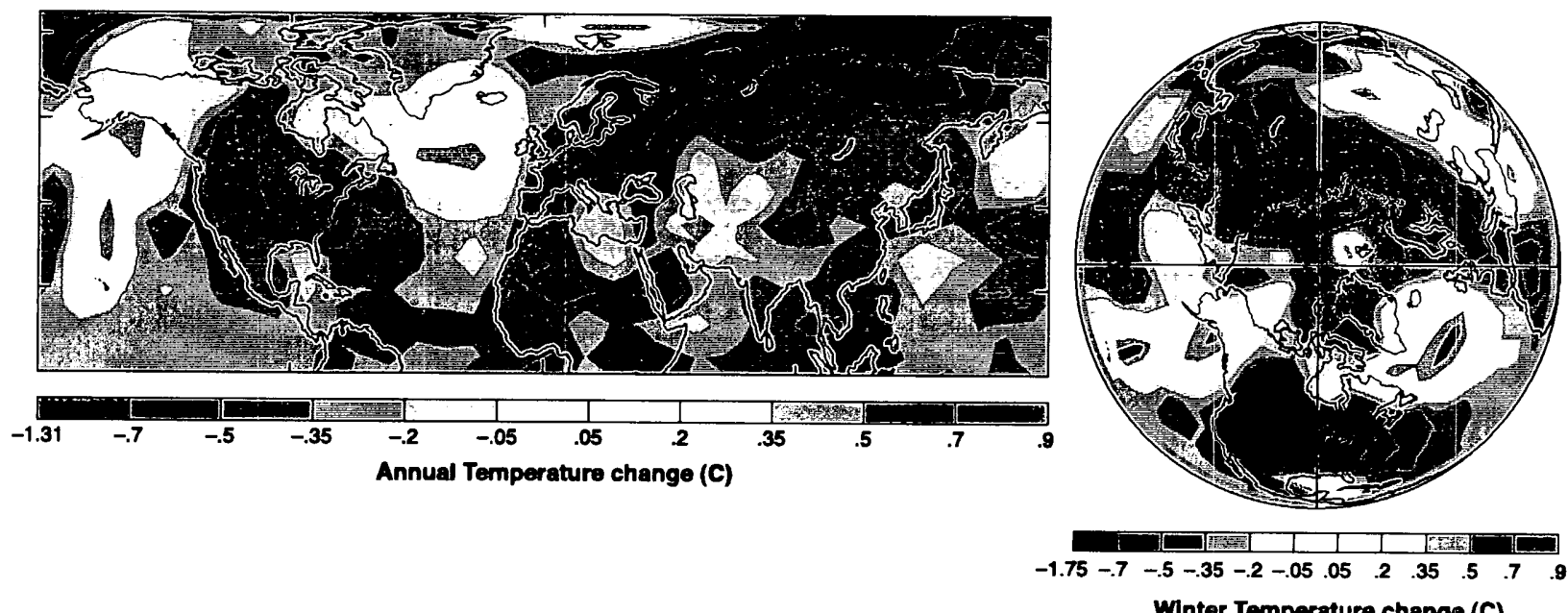

Winter Temperature change (C)

Fig. 1. Surface temperature change (in ${ }^{\circ} \mathrm{C}$ ) from 1780 to 1680 in the GCM. Global annual average (left) and November to April NH extratropics (right) are shown. Nearly all points are statistically significant (not shown) because of the large number of model years. Data for all figures are available as online supplemental material (40).
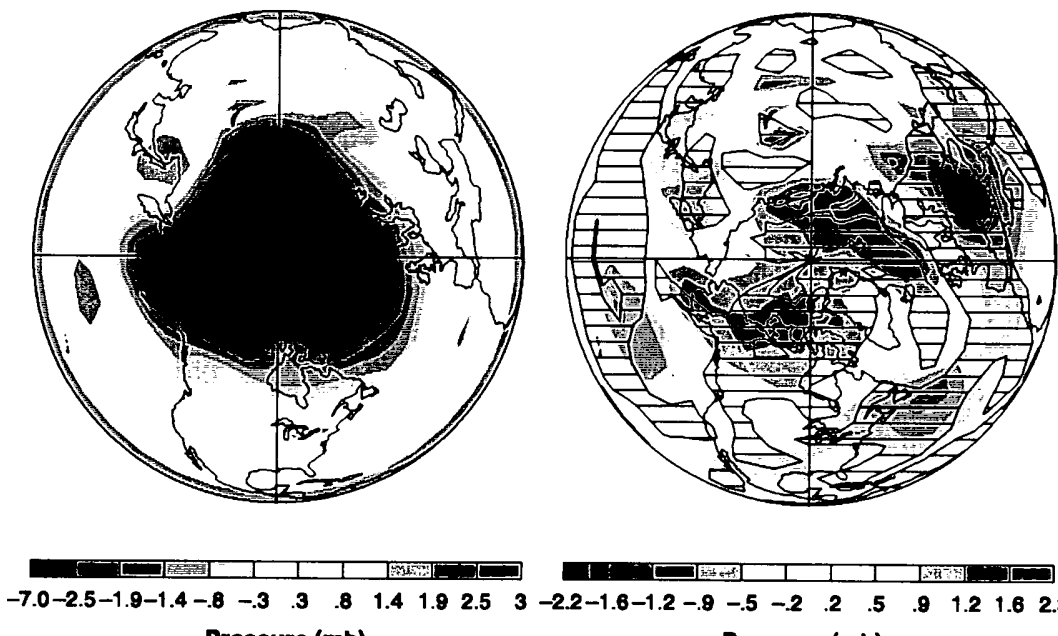

Preasure (mb)

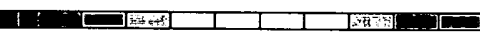

$-2.2-1.6-1.2-9-5-2.2 .5 .9+1.21 .62 .3$

Proasuro (mb)

Fig. 2. The leading EOF of NH extratropical November-to-April SLP over the past 40 years of the 1680 and 1780 simulations (left), and the SLP change from 1780 to 1680 (right), both in mbar $(\mathrm{mb})$. The SLP difference is filtered in EOF space by showing the projection onto the first 20 EOFs, which contain $70 \%$ of the total difference. This removes some of the high-frequency noise in the model induced by overly large energies at high wavenumbers. Hatched areas indicate statistical significance at the $90 \%$ level.

land (23), which is consistent with a reduced NAO but not with uniform basin-wide cooling. Other evidence suggests colder North Atlantic temperatures during those centuries, however, including evidence for increased sea ice around Iceland (24), a region of minimal change in the GCM.

Our previous studies have demonstrated how external forcings can excite the $\mathrm{AO}$ / NAO in the GISS GCM $(22,25)$. Briefly, the mechanism works as follows, using a shift toward the high-index AO/NAO as an example: (i) tropical and subtropical SSTs warm, leading to (ii) a warmer tropical and subtropical upper troposphere via moist convective
$(27,28)$, and zonal wind and planetary wave propagation changes over recent decades are well reproduced in the model (22).

Reduced irradiance during the Maunder Minimum causes a shift toward the low-index AO/NAO state via this same mechanism. During December to February, the surface cools by $0.4^{\circ}$ to $0.5^{\circ} \mathrm{C}$ because of reduced incoming radiation and the upper stratospheric ozone increase. Cooling in the tropical and subtropical upper troposphere is even more pronounced $\left(\sim 0.8^{\circ} \mathrm{C}\right)$ because of cloud feedbacks, including an $\sim 0.5 \%$ decrease in high cloud cover induced by ozone through surface effects. A similar response was seen in simulations with a finer resolution version of the GISS GCM (14). This cooling significantly reduces the latitudinal temperature gradient in the tropopause region, decreasing the zonal wind there at $\sim 40^{\circ} \mathrm{N}$. Planetary waves coming up from the surface at midlatitudes, which are especially abundant during winter, are then deflected toward the equator less than before (equatorward Eliassen-Palm flux is reduced by $0.41 \mathrm{~m}^{2} / \mathrm{s}^{2}, 12^{\circ}$ to $35^{\circ} \mathrm{N}, 300$ to 100 mbar average), instead propagating up into the stratosphere (increased vertical flux of $6.3 \times 10^{-4} \mathrm{~m}^{2} / \mathrm{s}^{2}, 35^{\circ}$ to $60^{\circ} \mathrm{N}, 100$ to $5 \mathrm{mbar}$ average) (29). This increases the wave-driven stratospheric residual circulation, which warms the polar lower stratosphere (up to $1^{\circ} \mathrm{C}$ ), providing a positive feedback by further weakening the latitudinal temperature gradient. The wave propagation changes imply a reduction in northward angular momentum transport, hence a slowing down of the middle- and high-latitude westerlies and a shift toward the low AO/NAO index. Because the oceans are relatively warm during the winter owing to their large heat capacity, the diminished flow creates a 
REPORTS
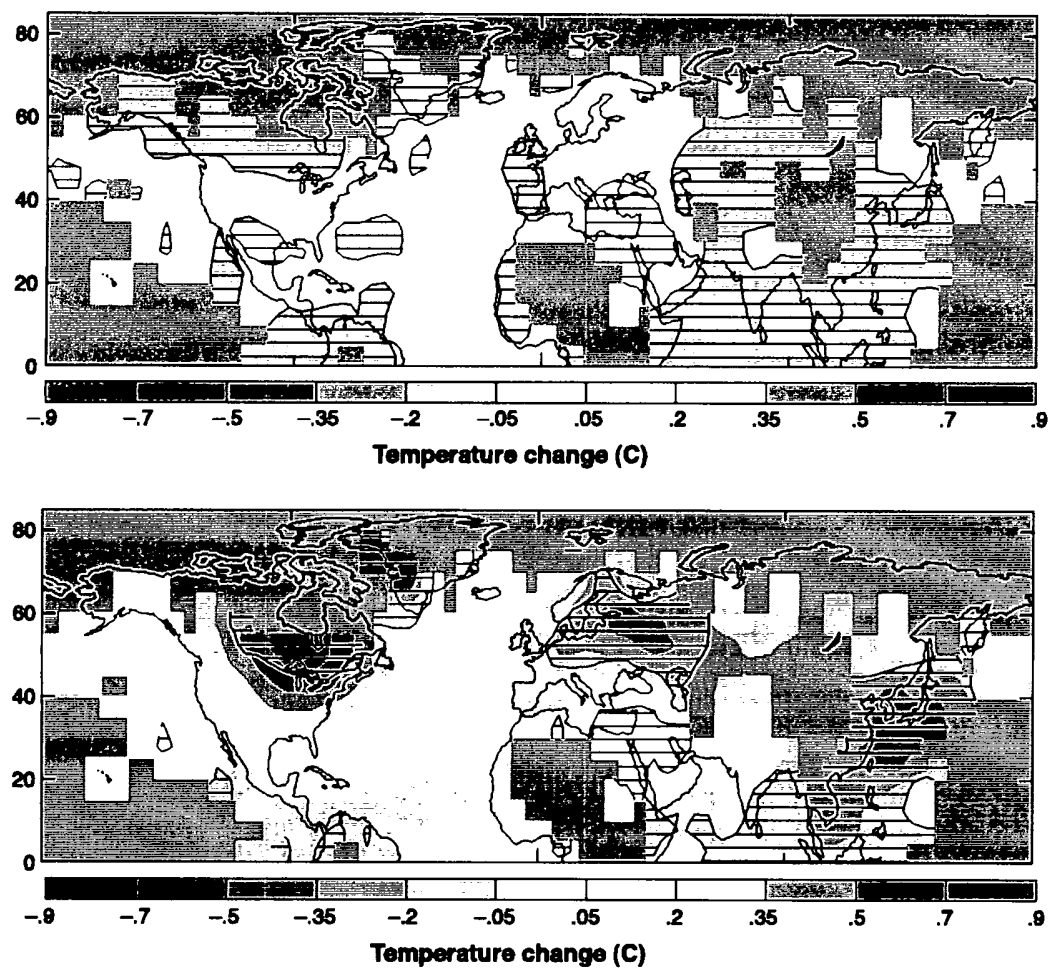

Fig. 3. Regression during the period from 1650 to 1850 between reconstructed solar irradiance (1) and annual average surface temperatures (19). The top panel shows the instantaneous regression over all time scales, whereas the bottom panel shows the regression when filtered to only include contributions from time scales longer than 40 years, with a 20 -year lag (results are similar for time lags of 10 to 30 years). The correlation is given in ${ }^{\circ} \mathrm{C}$ per $-0.32 \mathrm{~W} / \mathrm{m}^{2}$ (the solar forcing used in the model) for comparison with the modeled temperature changes shown in Fig. 1. Gray areas indicate no data; hatched areas indicate statistical significance at the $90 \%$ level.

cold-land/warm-ocean surface pattern (Fig. 1).

To quantify the importance of ozone changes, an identical pair of 1680 and 1780 experiments was run, leaving out the ozone response. These simulations show a reduction in the $\mathrm{AO}$ index of only $0.5 \mathrm{mbar}$, and the SLP change projection onto the $A O$ was $15.1 \%$. Thus, there was an analogous but weaker response without interactive ozone. The ozone changes further reduce the tropopause radiative forcing by $-0.02 \mathrm{~W} / \mathrm{m}^{2}$ (instantaneous, but with adjusted stratospheric temperatures) for 1680 conditions (compared to the direct solar forcing of $\left.-0.32 \mathrm{~W} / \mathrm{m}^{2}\right)$. Cloud feedbacks caused by ozone magnify its influence somewhat, so that the global annual average surface temperature change increases from $-0.28^{\circ} \mathrm{C}$ to $-0.34^{\circ} \mathrm{C}$, including ozone chemistry. The largest impacts resulted from the enhancement of the tropopause region latitudinal temperature gradient through high cloud changes and subsequent wave-driven feedbacks.

In contrast to the preindustrial simulations, 20th-century simulations (30) show that solar irradiance changes alone warm the surface by $\sim 0.25^{\circ} \mathrm{C}$, but when ozone changes and climate feedbacks are included, the cooling drops to $\sim 0.19^{\circ} \mathrm{C}$. With current atmospheric composition, ozone enhancement from increased irradiance outweighs temperature-induced changes, leading to more middle and upper stratospheric ozone (9), which dampens the net radiative forcing. Ozone's reversal from a positive (preindustrial) to a negative feedback supports results showing that solar forcing has been a relatively minor contributor to late 20th-century surface warming $(7,19,31)$. However, ozone feedbacks remain important to the dynamical response associated with decadal and shorter term solar variability, which is initiated by upper stratospheric temperature changes, which are proportional to solar heating and hence to ozone (9).

The AO/NAO response is dependent on the overall forced change in tropical and subtropical SSTs, translation of these changes into upper tropospheric temperature changes by hydrological feedbacks, and the resulting wind and planetary wave refraction changes. These processes vary between models and in particular are sensitive to the inclusion of a realistic stratosphere $(22,25)$, emphasizing the need for intermodel comparisons of sim- ilar experiments (32).

The ECHAM3 GCM exhibits a similar spatial pattern of response to solar forcing, with warming over the $\mathrm{NH}$ continents and cooling over the North Atlantic and North Pacific (33). In that model, however, the surface temperature and AO sensitivity were much less than in our simulation. This is probably due to the lack of interactive ozone and the poorly resolved stratosphere, two important positive feedbacks in our model.

The importance of SST changes to initiate the AO/NAO response is consistent with our fixed-SST solar cycle experiments $(9,22)$, whose response did not project strongly onto the AO/NAO, and with the weak empirical instantaneous climate sensitivity (Fig. 3, top). Present-day observations and modeling al so support links between long-term tropical SST changes and the NAO $(34,35)$.

Surface temperatures in an energy balance model (36) driven by volcanic forcing gave a poor correlation with proxies during the 17 th and 18 th centuries. Correlations between calculations of solar-induced climate change and temperature proxies were quite good, however, although the impacts were very small. Inclusion of ozone chemical feedback would amplify the response, potentially reproducing observed amplitudes as well as variability.

The GISS model results and empirical reconstructions both suggest that solar-forced regional climate changes during the Maunder Minimum appeared predominantly as a shift toward the low AO/NAO index. Although global average temperature changes were small, modeled regional cooling over the continents during winter was up to five times greater. Changes in ocean circulation were not considered in this model. However, given the sensitivity of the North Atlantic to $\mathrm{AO} /$ NAO forcing (37), oceanic changes may well have been triggered as a response to the atmospheric changes (38). Such oceanic changes would themselves further modify the pattern of SST in the North Atlantic (39) and, to a lesser extent, the downstream air temperature anomalies in Europe.

These results provide evidence that relatively small solar forcing may play a significant role in century-scale $\mathrm{NH}$ winter climate change. This suggests that colder winter temperatures over the NH continents during portions of the 15th through the 17th centuries (sometimes called the Little Ice Age) and warmer temperatures during the 12th through 14th centuries (the putative Medieval Warm Period) may have been influenced by longterm solar variations.

References and Notes

1. J. Lean, J. Beer, R. Bradley, Geophys. Res. Lett. 22, 3195 (1995).

2. E. Bard et al., Tellus B 52, 985 (2000). 


\section{REPORTS}

3. M. Stuiver, T. F. Braziunas, Radiocarbon 35, 137 (1993).

4. K. Briffa et al., Nature 393, 350 (1998).

5. P. Jones et al., Holocene 8, 455 (1998).

6. M. E. Mann, R. S. Bradley, M. K. Hughes, Geophys. Res Lett. 26, 759 (1999)

7. T. J. Crowley, Science 289, 270 (2000).

8. C. Pfister, in Climate Since A.D. 1500 , R. S. Bradley, P. D. Jones, Eds. (Routledge, London, 1995), pp. 118 142.

9. D. T. Shindell, D. Rind, N. Balachandran, J. Lean, P. Lonergan, Science 284, 305 (1999).

10. D. T. Shindell, D. Rind, P. Lonergan, J. Clim. 11, 895 (1998)

11. D. J. Wuebbles, C.-F. Wei, K. O. Patten, Geophys. Res. Lett. 25, 523 (1998)

12. Because $2 D$ photochemical models have difficulty accounting for the dynamically driven stratospheric hydrological cycle, we prescribed stratospheric water vapor changes due to methane oxidation by conserving $x \times x \times x \times x\left(2 \times \mathrm{CH}_{4}+\mathrm{H}_{2} \mathrm{O}\right)$, which satellite data show is roughly constant. Long-term methane trends were taken from ice core data which show approximately $60 \%$ less methane durwhich show approximately ing the preindustral period. Observations from the HALOE instrument, version 18 data, obtained from the NASA Langley data center, were used to determine the fraction of methane oxidized throughout the stratosphere. For example, at $1 \mathrm{mbar}$ in mid-latitudes, -1.6 parts per million by volume (ppmv) of water was removed relative to the present based on $80 \%$ oxidation of the 1.0-ppmv methane change. This assumes that the preindustrial methane oxidation rate in the stratosphere was as large as that at present. This is fundamental to the negative ozone response, which differs from that seen in a previous study (11)

13. Ozone's temperature sensitivity is governed by catalytic cycles involving chlorine, nitrogen, hydrogen, and oxygen radicals. The temperature dependence of the rate-limiting reactions for the chlorine, nitrogen, and hydrogen cycles is weakly negative, whereas for oxygen it is strongly positive. The relative importance of the oxygen cycle was greater during the preindustrial period, leading to large increases in overall temperature sensitivity in the upper stratosphere.

14. J. Hansen, M. Sato, R. Ruedy, J. Geophys. Res. 102 6831 (1997).

15. D. V. Hoyt, K. H. Schatten, J. Geophys. Res. 98 , 18,895 (1993)

16. D. W. J. Thompson, J. M. Wallace, Geophys. Res. Lett. 25. 1297 (1998).

17. J. M. Wallace, Quart. J. Rxoxxx Meterol. Soc. 126, 791 (2000).

18. V. C. Slonosky, P. D. Jones, T. D. Davies, int. J. Climatol. 21, 285 (2001)

19. M. E. Mann, R. S. Bradley, M. K. Hughes, Nature 392. 779 (1998).

20. Because the pattem reconstructions are smoothed by retaining only a truncated eigenvector basis set, the amplitude of regional temperature variations is generally underestimated. This is particularly true before 1730, when five or fewer eigenvectors are retained.

21. A. M. Waple, M. E. Mann, R. S. Bradley, Clim. Dyn., in press.

22. D. T. Shindell, G. A. Schmidt, R. L. Miller, D. Rind, J. Geophys. Res. 106, 7193 (2001).

23. L. D. Keigwin, R. S. Pickart, Science 286, 520 (1999).

24. P. Bergthórsson, Jàkull 19, 94 (1969)

25. D. T. Shindell, R. L Miller, G. A. Schmidt, L Pandolfo, Nature 399, 452 (1999).

26. For forcing by greenhouse gases, the enhanced latitudinal gradient is further strengthened by their cooling effect in the stratosphere. Ozone depletion and volcanic forcing enhance the $\mathrm{AO}$ by an abbreviated mechanism, directly altering temperatures near the tropopause as in step (iii).

27. Y. Ohhashi, K. Yamazaki, J. Meteorol. Soc. Jpn. 77. 495 (1999).

28. D. L Hartmann, J. M. Wallace, V. Limpasuvan, D. W. J.
Thompson, J. R. Holton, Proc. Natl. Acad. Sci. U.S.A 97, 1412 (2000).

29. The flux changes are roughly $-1 / 3$ those seen in our greenhouse gas forcing simulations $(22,25)$, which is consistent with the $A O$ response ratio.

30. Temperature change was calculated as the difference between simulations, using 1900 and $1990 \mathrm{~s}$ irradiance, both with 1990s atmospheric composition. However, the influence of irradiance changes cannot be fully separated from that of the changing atmospheric composition on ozone photochemistry or the nonlinear long-term dynamical and chemical responses.

31. G. C. Hegerl et al., Clim. Dyn. 13, 613 (1997)

32. N. Gillett et al., J. Geophys. Res., in press.

33. U. Cubasch et al., Clim. Dyn. 13, 757 (1997)

34. B. Rajagopalan, Y. Kushnir, Y. M. Tourre, Geophys. Res. Letr. 25. 3967 (1998).

35. M. P. Hoerling J. W. Hurrell, T. Xu, Science 292, 90 (2001)

36. M. Free, A. Robock, J Geophys, Res, 104, 19,057 (1999).

37. T. L Delworth, K. W. Dixon, Clim 13, 3721 (2000)

38. W. S. Broecker, Proc. Natl. Acad. So U.S.A. 97,1339 (2000)

39. M. Visbeck, H. Cullen, G. Krahmann, N. Naik, Geophys. Res. Lett. 25, 4521 (1998)

40. Supplemental Web material is available on Science Online at uww.sciencemag.org/cgi/content/full VOL/ISSUE/PACE/DC1.

41. Stratospheric climate modeling at GISS is supported by NASA's Atmospheric Chemistry Modeling and Analysis Program. C.A.S. and D.T.S. acknowledge the support of NSF grant ATM-00-02267. M.E.M. acknowledges support from the National Oceanic and Atmospheric Administration- and NSF-supported Earth Systems History program. We thank J. Lean for providing the solar irradiance reconstruction.

13 Juty 2001; accepted 31 October 2001

\section{Article is $\mathbf{5 8 5}$ picas}

